\title{
Preparation of Biocompatible Magnetic Microspheres with Chitosan
}

\author{
Mohamed K. Nasra, Moustafa M. Mohamed, Mohamed A. Elblbesy, Bothaina A. Hefney
}

Medical Biophysics Departement, Medical Research Institute, Alexandria University, Alexandria, Egypt.

Email: M.Abdulaziz.Elblbesy@gmail.com

Received January $20^{\text {th }}, 2011$; revised February $22^{\text {nd }}, 2011$; accepted March $1^{\text {st }}, 2011$.

\begin{abstract}
Microsphere is a term used for small spherical particles, with diameters in the micrometer range (typically $1 \mu \mathrm{m}$ to $1000 \mu \mathrm{m}(1 \mathrm{~mm}))$. Microspheres are sometimes referred to as microparticles. Microspheres can be manufactured from various natural and synthetic materials. The present work we prepared chitosan magnetic microspheres (CMMS) with simple crosslinking method. The obtained CMMS were in size range of 1000 - $2600 \mathrm{~nm}$ with average particle size of $1800 \mathrm{~nm}$. All the essential characterizations of prepared CMMS were done and the results were in a good agreement with other magnetic microspheres prepared with different method. To test the biocompatibility of CMMS with blood, the effect of them on erythrocytes aggregation and blood hemolysis were studied. Our results showed that CMMS work as good compatible materials with blood.
\end{abstract}

Keywords: Magnetic, Microspheres, Chitosan

\section{Introduction}

Monodispersed nano/micrometer scale magnetic particles have drawn considerable attention because of both fundamental physics involved and technical applications in high-density magnetic storage media, ferrofluids and catalysts. The nano/micrometer spinel ferrite particles have great potential applications since they are relatively inert and their magnetic properties can be finely tuned by chemical manipulations. Especially, in recent years, the interests in monodispersed spinel ferrite nano/micrometer particles are growing based on their potential applications in biomedicine and biotechnology for contrast enhancement of magnetic resonance imaging (MRI) and as drug carriers for magnetically guided site-specific drug delivery [1].

Magnetic nanoparticles offer some attractive possibilities in biomedicine. First, they have controllable sizes ranging from a few nanometers, which places them at dimensions that are smaller than or comparable to those of a cell $(10-100 \mu \mathrm{m})$, a virus $(20-450 \mathrm{~nm})$, a protein $(5-50 \mathrm{~nm})$ or a gene ( $2 \mathrm{~nm}$ wide and $10-100 \mathrm{~nm}$ Iong). This means that can 'get close' to a biological entity of interest. Indeed, they can be coated with biological molecules to make them interact with or bind to a biological entity, thereby providing a controllable means of "tag- ging" or addressing it. Second, the nanoparticles are magnetic, which means that they obey Coulomb's law, and can be manipulated by an external magnetic field gradient. This 'action at a distance', combined with the intrinsic penetrability of magnetic fields into human tissue, opens up many applications involving the transport and/or immobilization of magnetic nanoparticles, or of magnetically tagged biological entities. In this way they can be made to deliver a package, such as an anticancer drug, or a coherent of radionuclide atoms, to a targeted region of the body, such as a tumor. Third, the magnetic nanoparticles can be made to resonantly respond to a time-varying magnetic field, with advantageous results related to the transfer of energy from the exciting field to the nanoparticles [2].

In recent years, a large number of different clinical applications of magnetic microspheres have been proposed, mainly connected to disease treatments. On the contrary, only few others have proposed to use nanoparticles for the reliable detection and localization of tumors. Magnetic drug delivery by particulate carriers is a very efficient method of delivering a drug to a localized disease site. In magnetic targeting, a drug or therapeutic radioisotope is bound to a magnetic compound, injected into a patient's blood stream, and then stopped with a powerful magnetic field in the targeted area [3]. 
There is a considerable interest in preparation of magnetite $\left(\mathrm{Fe}_{3} \mathrm{O}_{4}\right)$ due to its strong magnetic properties, which were used first in biology and then in medicine for the magnetic separation of biochemical products and cells as well as the magnetic guidance of particle systems for site-specific drug delivery. However, the size, charge, and surface chemistry of magnetic particles could strongly influence their magnetic properties and distribution in biological systems. The most common method for the synthesis of magnetite is by co-precipitation from a solution of $\mathrm{Fe}$ (III) and $\mathrm{Fe}$ (II) salts in presence of base. Preparation of size-controllable magnetite nano-particles was performed in presence of different water-soluble polymers such as lignosulfonate, mesoporous sulfonated styrene-divinylbenzene, polypeptide $[4,5]$ etc.

Magnetite nano-particles have been also incorporated into more complicated architectures, such as polymeric gels providing formation of magnetic field sensitive gels [6]. These gels contain magnetic particles dispersed homogeneously and confined in a polymer network. Under a nonuniform magnetic field, the particles undergo motion; which in turn induces elongation, contraction, or bending of the gels with short response time. Incorporation of magnetite into spherical polymeric particles has been achieved by following two approaches: 1) heterocoagulation of magnetite on the surface of pre-formed polymeric particles [7], 2) encapsulation of magnetite particles during emulsion polymerization process [8] or by using the microemulsion approach [9], or 3) by layer-by-layer deposition method $[10,11]$.

As the pharmaceutical industry continues to develop new effective medications, the need to develop efficient, minimally invasive delivery techniques is paramount. A successful targeted drug delivery system will allow clinical usage of drug not currently accessible to physicians, as well as a more efficient means for delivering those already available [12].

Chitosan is a heteropolysaccharide composed of $\beta$ (1-4)-2-deoxy-2-amino-d-glucopyranose units and of $\beta$ (1-4)-2-deoxy-2-acetamino-d-glucopyranose units. Chitosan occurs in nature, particularly in the cell wall of some fungi such as Mucor rouxii [13] and is mainly produced by the deacetylation of chitin, which is a major component of the exoskeleton of insects, the cuticles of annelids and mollusks, and the shell of crustaceans such as shrimp, crab, and lobster. Chitosan has been extensively examined in the pharmaceutical industry for its potential in the development of controlled release of drug delivery due to its excellent biocompatibility, biodegradability, bioactivity and nontoxicity [14]. Various sustained release drug carriers have been made from chitosan such as microparticles [15], tablets [16], gel [17] and beads [18]. Chitosan microspheres have been widely investigated for use as controlled release delivery sys- tems for hormones [19], vitamins [20], proteins [21] and enzymes [22].

This work aims to prepare the chitosan magnetic microspheres and to study its effect on dynamic properties (blood viscosity, erythrocytes aggregation, osmotic fragility and hemolysis) (in vitro) under the influence on external magnetic field.

\section{Materials and Methods}

Chitosan polymer, glutraldhyde, Sodium hydroxide, ferrous sulfate, ferric chloride, sodium hydroxide and polyethylene glycol-10000 (PEG-10000) were obtained from Sigma (UAS). All chemicals were of analytical grade and no further purification was required.

\section{Preparation of Chitosan Magnetic Microspheres}

Acetate buffer was used as solvent for the chitosan polymer and glutraldhyde was used as the cross-linker. Sodium hydroxide solution was used as medium. Magnetic fluid was synthesized as follows: a $35 \%(w / v)$ ferrous sulfate solution, $54 \%(\mathrm{w} / \mathrm{v})$ ferric chloride solution and $36 \%(\mathrm{w} / \mathrm{v})$ sodium hydroxide solution were prepared using distilled water. Then the ferric salt and ferrous salt were mixed, stirred and heated. When the temperature reached $55^{\circ} \mathrm{C}$, the alkaline solution was added. The mixture was stirred for $30 \mathrm{~min}$, and then $5 \mathrm{~g}$ of polyethylene glycol-10000 (PEG-10000) was added. The temperature was raised to $80^{\circ} \mathrm{C}$ and maintained for $30 \mathrm{~min}$. The mixture was then neutralized while cooling, and the magnetic fluid was prepared. $1 \%(\mathrm{w} / \mathrm{w})$ chitosan was dissolved in acetate buffer at $\mathrm{pH}$ 4.5. The dissolved chitosan was added drop wise on the magnetic fluid using Syringe Pump. Formed CMMS were washed with deionized water and soaked in 1, 3, and $5 \mathrm{~mol} \%$ glutraldhyde solution for $2 \mathrm{hr}$, and then washed with deionized water.

Scanning electron microscopy (SEM) (Joel, JSM-6360 LA-Japan) images were taken after sputter coating the CMMS with gold (SPI-module TM Sputter coater, Japan).the size of CMMS was analyzed by Beckman Coulter Particle Size Analyzer (N5 submicron particle size analyzer, Japan). The magnetic properties of air dried MMS were determined by a vibrating-sample magnetometer (VSM-9600-1DSM-LDG-USA). Thermo gravimetric analyses (TGA) were measured by (Shimadzu, TGA-50, Japan) with a heating rate of $10^{\circ} \mathrm{C} / \mathrm{min}$ in nitrogen flow. Fourier transforms infrared spectrophotometer (FT-IR) spectra were recorded before and after processing of CMMS. The FTIR spectra were obtained using a FT-IR spectrophotometer (Alpha-centauri) (Shimadzu, Japan, FT-IR-8400S). Around 4 - 8 mg of MMS were thoroughly mixed with IR-grade potassium bromide (KBr) $(200 \mathrm{mg})$ and grinding together, then compressed into tablet form with the compressor (Shimadzu-Compressor-Japan) in order to record the spectrum. 


\section{Microscopic Study of RBC's Aggregation}

For examine the effect of CMMS on erythrocytes aggregation. $2 \mathrm{ml}$ of erythrocytes suspension with $1 \%$ concentration in PBS was incubated with $1 \mathrm{gm}$ of CMMS for two hours. The incubated erythrocytes were then allowed to immigrate freely on an inclined slide at angle of $45^{\circ}$ in order to make erythrocytes film [23]. Erythrocytes film was left to dry for two minutes. The erythrocytes film was examined using light microscope connected to CCD camera. The image of erythrocytes film was transferred to computer through an interface connected to CCD camera. The images of erythrocytes film were analyzed by imaging processing software in order to calculate aggregation shape parameter (ASP) which is used to quantify erythrocytes aggregation. The following equation was used to calculate ASP [24]:

$$
\mathrm{ASP}=4 \pi \mathrm{A} / \mathrm{P}^{2}
$$

where $\mathrm{A}$ is the projected area of the aggregate, $\mathrm{P}$ is the perimeter of the projected area. The ASP of ten images of incubated erythrocytes was computed in order to calculate the mean value of ASP and then compared to the mean value of unincubated erythrocytes.

\section{Hemolysis}

Hemolysis has been determined to confirm that the chosen magnetic field intensity for the chosen time period affects the cellular membrane. Erythrocyte suspensions $(\mathrm{Ht}=5 \%)$ was incubated with CMMS, for two hours. After centrifugation the degree of hemolysis (\%) was determined by measuring the hemoglobin content in the supernatant at $540 \mathrm{~nm}$. Hemolysis was expressed as a percentage of the absorbance in distilled water [25].

\section{Results and Discusssion}

The observation of size,shape and surface topography of the dried CMMS are shown in Figure 1.The shapes of the dries microspheres were soherical, and the surface was rough, porous and unfolded. Furthermore the microsphere was not hollow.

The particle size distribution curve (Figure 2.) showed sharp distribution range of microspheres, with $90 \%$ of spheres in size range of 1000-2600 nm with average particle size of $1800 \mathrm{~nm}$ and only $10 \%$ were oversized. The formed microspheres have uniform surface structure in which the microspheres lose their shape upon drying but regain them upon re-swelling. Which agreement with the results obtained by Erika Aranas et al. [26]. Erika Aranas et al. [26] prepared the spheres with technique similar to emulsion polymerization. Zhanga Ji et al. prepared composite magnetic microspheres based on artemisia seed gum and chitosan using the suspension cross-linking technique for use in the application of magnetic carrier technology [27]. Their results showed that composite

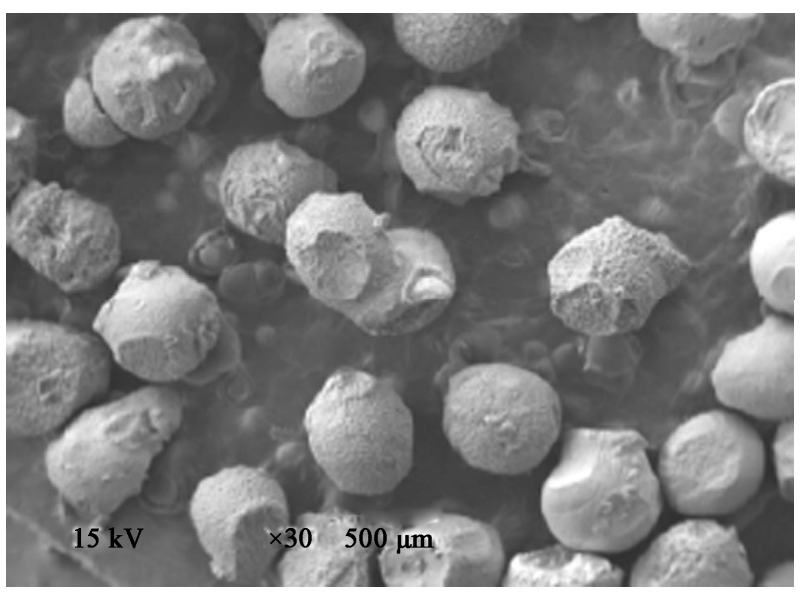

(a)

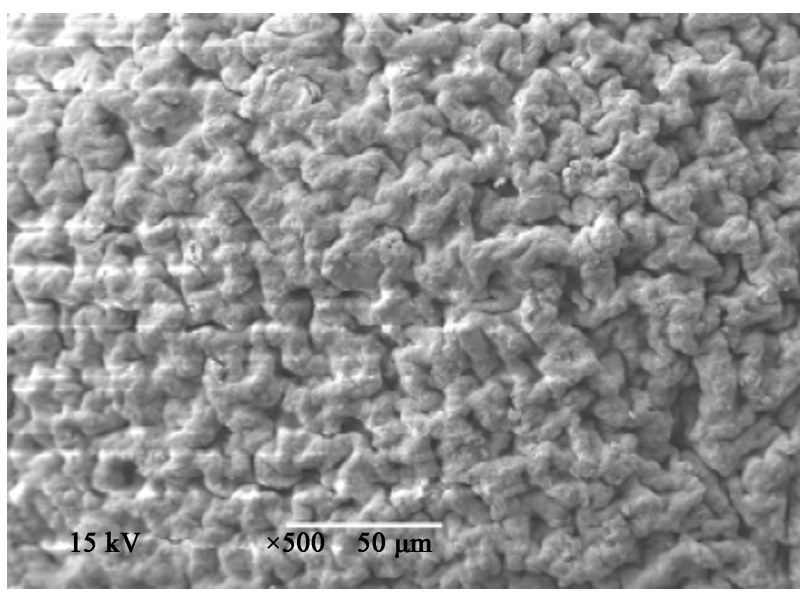

(b)

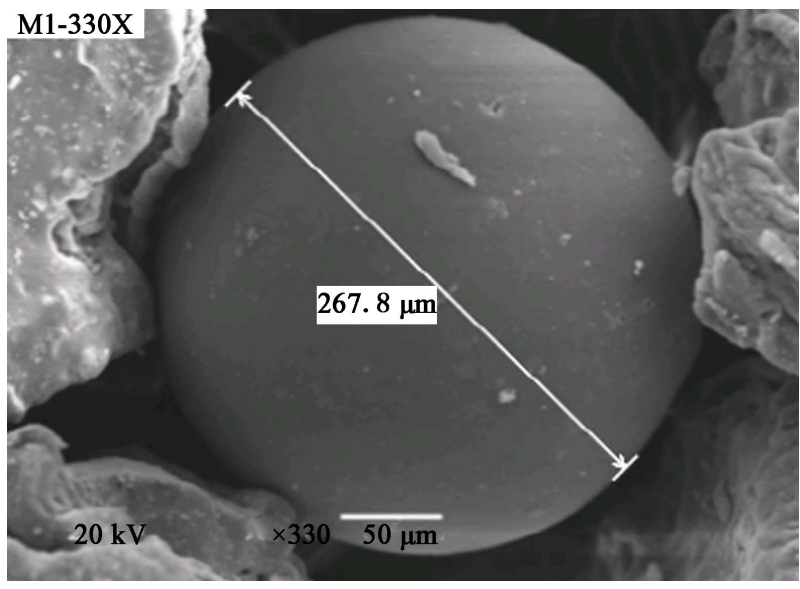

(c)

Figure 1. SEM images of CMMS (a) CMMS with different size; (b) Rough surface of CMMS; (c) None hollow CMMS.

magnetic microspheres can be produced in the size range $230-460 \mu \mathrm{m}$. 
\$90.0, Repetltion 1 Unimedal Distribution Results Unimodal Results Summary

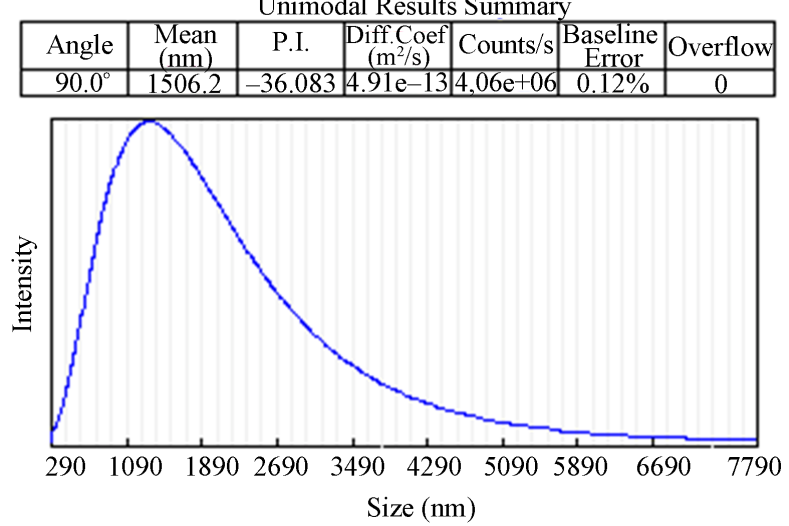

Figure 2. Particles size distribution of CMMS with size range $1000-2600 \mathrm{~nm}$.

From the hysteresis loops of CMMS (Figure 3), the saturation magnetization was $8.065 \mathrm{emu} / \mathrm{g}$, coercivity was $76.05 \mathrm{Oe}$ and retentivity was $1.057 \mathrm{emu} / \mathrm{g}$. These results are in agreement with Zhanga $\mathrm{Ji}$ et al. the magnetic properties of the composite magnetic microspheres were evaluated using a VSM [27].

The most effective parameters determining the magnetic properties were the stirring rate of the suspension medium and the $\mathrm{Fe}_{3} \mathrm{O}_{4} /$ chitosan ratio, as in the case of the size/size distribution evaluation. The stirring rate of the suspension medium was varied between 500 and $1000 \mathrm{rpm}$ for investigation of the effects of stirring rate on the magnetic properties of the composite magnetic microspheres. Furthermore, similar behavior for this parameter had been reported previously. Chiriac H. et al., showed that the variation of the saturation magnetization and the coercive field as a function of the particle sizes for the atomized magnetic microspheres obtained for a diameter nozzle of $91 \mathrm{~mm}$ [28]. Their result showed that the saturation magnetization and the coercive field of the atomized microspheres with sizes between 26 and 300 $\mathrm{mm}$ range between 79.8 and $42 \mathrm{emu} / \mathrm{g}$ and 305 and 384 Oe, respectively.

Thermal gravimetric Analysis (Figure 4.) showed that the chitosan powder a small peak at $26^{\circ} \mathrm{C}-106^{\circ} \mathrm{C}$ due to the volatization of the solvent. Other strong transitions were found at $253^{\circ} \mathrm{C}-337^{\circ} \mathrm{C}$ due to faster decomposition of chitosan powder. The difference in the thermal analysis between the two figures of chitosan powder and CMMS may be due to increase of thermal stability of magnetic microspheres than chitosan. This results in agreement with results obtained by Pich A. et al. [29]. Liu ZL et al. indicated that in their Thermal gravimetric Analysis of magnetic microspheres that the microspheres start degrading at about $260^{\circ} \mathrm{C}$. The first mass loss is about $63 \%$ at the temperature between 260 and $2801 \mathrm{C}$,

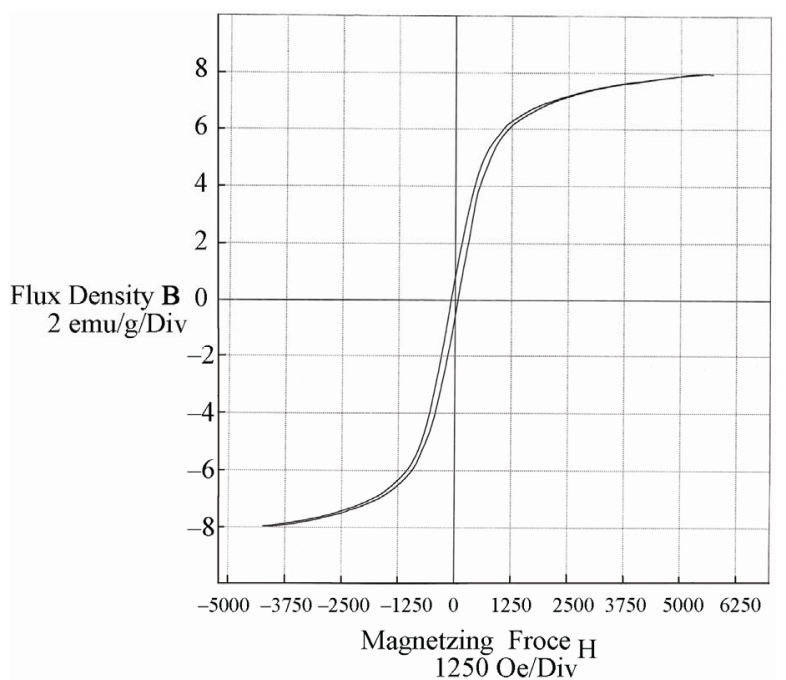

Figure 3. Hysteresis loop of CMMS.

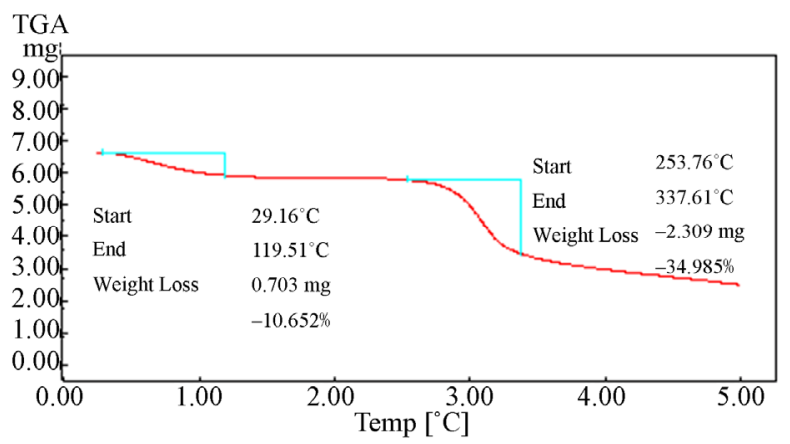

(a)

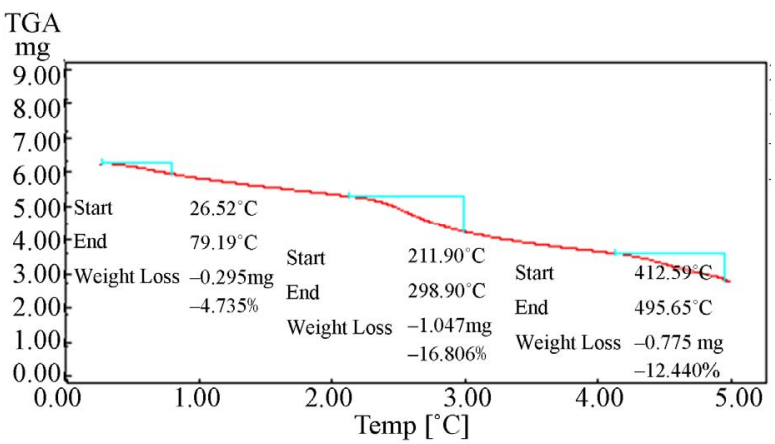

(b)

Figure 4. Thermal gravimetric analysis of chitosan (a) and CMMS (b).

and the second mass loss is about $10 \%$ at the temperature between 360 and $4001 \mathrm{C}$. The $\mathrm{Tg}$ is about 280 and 380 $1 \mathrm{C}$, respectively.

For the IR spectrum of chitosan (Figure 5) the characteristic absorption bands appeared at $3433 \mathrm{~cm}^{-1}$ indicate to hydroxyl group, $1641 \mathrm{~cm}^{-1}$ indicate to amide I, $1573 \mathrm{~cm}^{-1}$ indicate amide II, $1382 \mathrm{~cm}-1$ indicate to am- 


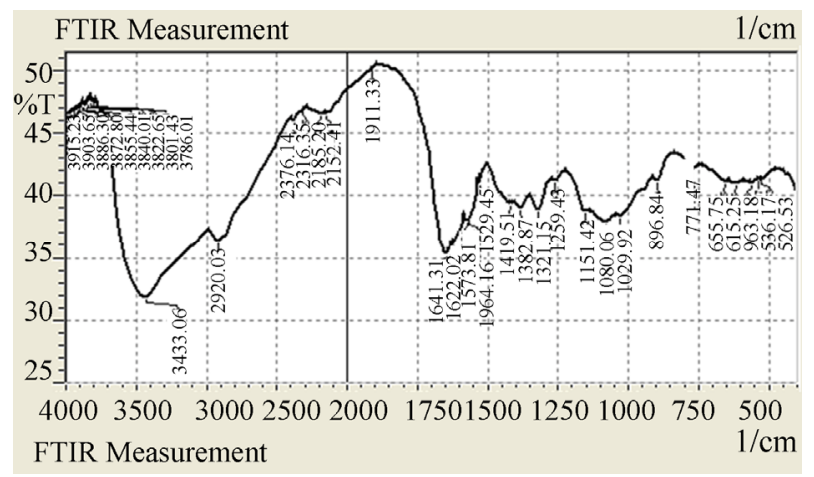

(a)

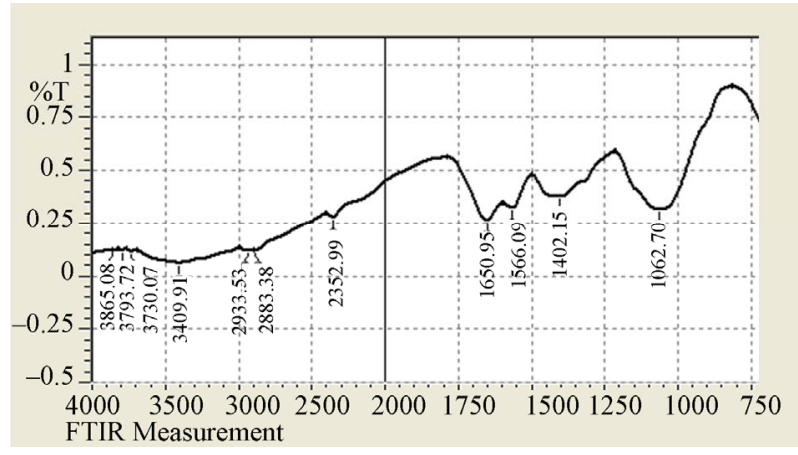

(b)

Figure 5. the IR spectrum of chitosan (a) and CMMS (b).

ide III, band at $2920 \mathrm{~cm}^{-1}$ indicate to C-H stretching of coplymer, band at $1029 \& 1080 \mathrm{~cm}^{-1}$ indicate to C-O stretching and band at $1622 \mathrm{~cm}^{-1}$ indicate to $\mathrm{NH} 3$ absorption of chitosan. Compared with the spectrum of chitosan magnetic microsphere (Figure 5) the $3433 \mathrm{~cm}-1$ peak of hydroxyl group shifted to $3409 \mathrm{~cm}^{-1}$ and a decrease in peak intensity of amid I $\left(-\mathrm{NH}_{2}\right)$ group at 1566 $\mathrm{cm}^{-1}$ which indicated the ionic cross-linking between amid $\mathrm{I}\left(-\mathrm{NH}_{2}\right)$ group of chitosan and $-\mathrm{C}=\mathrm{O}$ groups of glutraldhyde and new characteristic band appear at 1650 $\mathrm{cm}^{-1}$ indicate to $\mathrm{C}=\mathrm{N}$ group which indicate to crosslinking. The functional groups of materials are very important for diverse applications, especially for biotechnological purposes. Therefore, the present functional groups should be kept even if the shape (or geometry) is changed into a new form (i.e. microspheres or membrane). In this study the FT-IR of the spectra results obtained the peaks expected due to the geometry. In which the spectra of chitosan powder indicated the presence of the characteristic peaks such as hydroxyl group, amid-I, and amid-П, amid-III, and NH3 group. On the other hand the spectra of chitosan magnetic microspheres obtained shift in the characteristic peak of hydroxyl group and decrease in the peak intensity of amid-I due to the cross-linking between amid- and glutraldhyde which

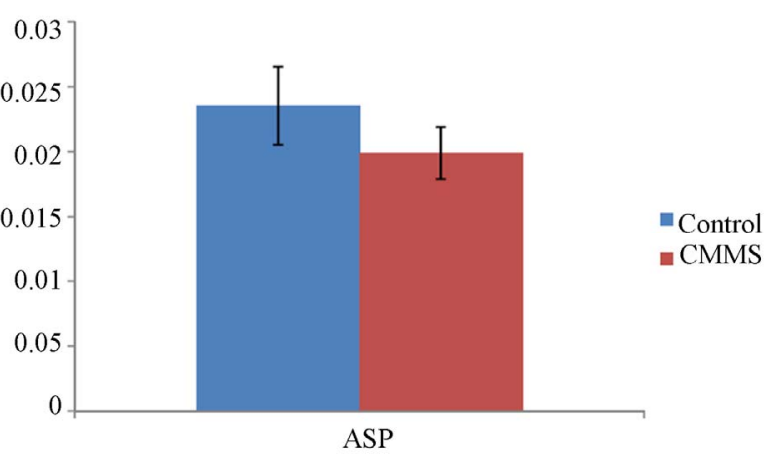

Figure 6. ASP of erythrocytes incubated with CMMS compared to control.

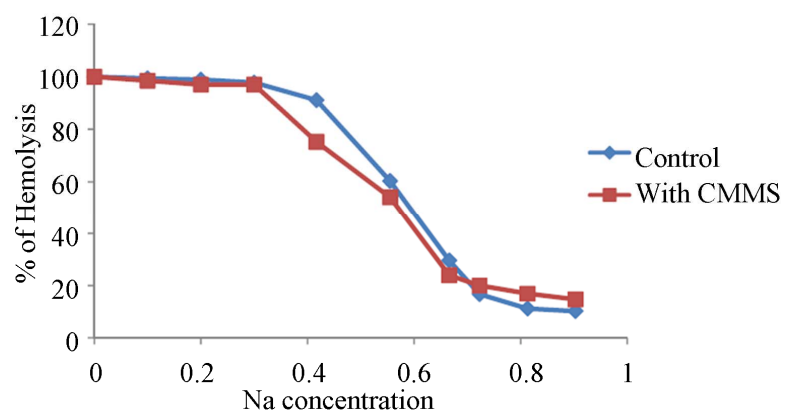

Figure 7. Hemolysis of blood incubated with CMMS.

obtained by the presence of characteristic peaks of $\mathrm{C}=\mathrm{N}$ group. In the FTIR spectra of magnetic chitosan microspheres obtained by De-Sheng J et al. the (C), the peak was at $3427 \mathrm{~cm}^{-1}$ corresponds to stretching vibrations of hydroxyl. The $\mathrm{C}-\mathrm{H}$ stretching vibration of the polymer backbone is manifested through strong peak at $2925 \mathrm{~cm}^{-1}$ and $2855 \mathrm{~cm}^{-1}$ [30]. The stretch vibrations of C-O are found at $1084 \mathrm{~cm}^{-1}$ and $1032 \mathrm{~cm}^{-1}$. For cross-linked chitosan microspheres, an additional peak at $1656 \mathrm{~cm}^{-1}$ which corresponds to stretching vibrations of $\mathrm{C}-\mathrm{N}$ bond. This peak indicates the formation of Schiff's base as a result of the reaction between carbonyl group of glutaraldehyde and amine group of chitosan chains. The little peak at $1721 \mathrm{~cm}^{-1}$ shows the existence of impendent aldehydic group in magnetic chitosan microspheres.

The erythrocytes incubated with CMMS showed lower values of ASP than control (unicubated erythrocytes) Figure 6. But the decrease in ASP was slightly small. This indicated that there was no harmful effect of CMMS on erythrocytes aggregation.

There was no difference in hemolysis curve between control and blood incubated with CMMS Figure 7. This make sure that CMMS have no harmful effect on blood.

\section{REFERENCES}

[1] J. H. Lee, C. K. Kim, S. Katoh and R. J. Murakami, "Mi- 
crowave-hydrothermal versus conventional hydrothermal preparation of Ni- and Zn-ferrite powders," Journal of Alloys and Compounds, Vol. 325, 2001, pp. 276-280. doi:10.1016/S0925-8388(01)01375-5

[2] J. Jansen and H. I. Maibach, "Encapsulation to deliver Topical Actives, in Handbook of Cosmetic Science and Technology," Marcel Dekker, New York, 2001.

[3] K. Kofuji, C. J. Qian, Y. Murata and S. Kawashima, "Preparation of Chitosan Microparticles by Water-inVegetable Oil Emulsion Coalescence Technique," Reactive and Functional Polymers, Vol. 62, 2005, pp. 77-83. doi:10.1016/j.reactfunctpolym.2004.09.002

[4] M. Fang, P. S. Grant, M. McShane, G. B. Sukhorukov, V. O. Golub and Y. M. Lvov, "Magnetic Bio/ Nanoreactor with Multilayer Shells of Glucose Oxidase and Inorganic Nanoparticles," Langmuir, Vol. 18, 2002, pp. 6338-6344. doi:10.1021/la025731m

[5] M. I. Papisov, A. Bogdanov Jr, B. Schaffer, N. Nossiff, T. Shen, R. Weisleder and T. J. Brady, "Colloidal Magnetic Resonance Contrast Agents: Effect of Particle Surface on Biodistribution," Journal of Magnetism and Magnetic Materials, Vol. 122, 1993, pp. 383-386. doi:10.1016/0304-8853(93)91115-N

[6] D. Rabelo, E. C. D. Lima, A. C. Reis, W. C. Nunes, M. A. Novak, V. K. Garg, A. C. Oliveira and P. C. Morais, "Preparation of Magnetite Nanoparticles in Mesoporous Copolymer Template," Nano Letters, Vol. 1, No.2, 2001, pp. 105-108. doi:10.1021/n1005533k

[7] T. Narita, A. Knaebel, J. P. Munch, S. J. Candau and M. Zrinyi, "In Physical Properties of Polymer Gels," Macromolecules, Vol. 36, 2003, pp. 2985-2989. doi:10.1021/ma025834b

[8] X. Xu, G. Friedman, K. D. Humfeld, S. Majetich and S. A. Asher, "Synthesis and Utilization of Monodisperse Superparamagnetic Colloidal Particles for Magnetically Controllable Photonic Crystals," Chemistry of Materials, Vol. 14, 2002, pp. 1249-1256. doi:10.1021/cm010811h

[9] D. Horak, B. Rittich, J. Safar, A. Spanova, J. Lenfeld and M. J. Benes, "Properties of RNase a Immobilized on Magnetic Poly (2-hydroxyethyl methacrylate) Microspheres," Biotechnology Progress, 2001, Vol. 17, pp. 447-452. doi:10.1021/bp0100171

[10] G. Mobe, K. Kon-no, K. Kyori and A. Kitahara, "Preparation and Characterization of Monodisperse Magnetite Sols in W/O Microemulsion," Journal of Colloid and Interface Science, Vol. 93, 1983, pp. 293-295. doi:10.1016/0021-9797(83)90411-3

[11] K. M. Lee, M. S. Corensen, J. K. Klabunde and G. C. Hadjipanayis, "Synthesis and Characterization of Stable Colloidal $\mathrm{Fe}_{3} \mathrm{O}_{4}$ Particles in W/O microemulsions," IEEE Transactions on Magnetics, Vol. 28, 1992, pp. 3180-3182. doi:10.1109/20.179751

[12] L. Liz, M. A. Lopez-Quintela, J. Mira and J. J. Rivas, "Preparati on colloidal $\mathrm{Fe}_{3} \mathrm{O}_{4}$ ultrafine particles in microemulsions," Journal of Materials Science, Vol. 29, 1994, pp. 3797-3801. doi:10.1007/BF00357351

[13] J. Synowiecki and N. A. A. Q. Al-Khateeb, "Mycelia of
Mucor rouxii as a Source of Chitin and Chitosan," Food Chemistry, Vol. 60, 1997, pp. 605-610. doi:10.1016/S0308-8146(97)00039-3

[14] C. M. Lehr, J. A. Bouwstra, E. H. Schacht and H. E. Junginger, "In Vitro Evaluation of Mucoadhesive Properties of Chitosan and Some Other Natural Polymers," International Journal of Pharmaceutics, Vol. 166, No. 1, 1998, pp. 75-88. doi:10.1016/0378-5173(92)90353-4

[15] S. A. Agnihotri and T. M. Aminabhavi, "Controlled Release of Clozapine through Chitosan Microparticles Prepared by a Novel Method," Journal of Controlled Release, Vol. 96, No. 2, 2004, pp. 245-259. doi:10.1016/j.jconrel.2004.01.025

[16] J. Nunthanid, M. Laungtana-anan, P. Sriamornsak, S. Limmatvapirat, S. Puttipipatkhachorn, L. Y. Lim and E. Khor, "Characterization of Chitosan Acetate as a Binder for Sustained Release Tablets," Journal of Controlled Release, Vol. 99, No. 1, 2004, pp. 15-26. doi:10.1016/j.jconrel.2004.06.008

[17] K. Kofuji, H. Akamine, C. J. Qian, K. Watanabe, Y. Togan, M. Nishimura, I. Sugiyama, Y. Murata and S. Kawashima, "Therapeutic Efficacy of Sustained Drug Release from Chitosan Gel on Local Inflammation," International Journal of Pharmaceutics, Vol. 272, No. 1-2, 2004, pp. 65-78. doi:10.1016/j.ijpharm.2003.11.036

[18] R. Barreiro-Iglesias, R. Coronilla, A. Concheiro and C. Alvarez-Lorenzo, "Preparation of Chitosan Beads by Simultaneous Cross-Linking/Insolubilisation in Basic $\mathrm{pH}$ Rheological Optimisation and Drug Loading/Release Behaviour," European Journal of Pharmaceutical Sciences, Vol. 24, No. 1, 2005, pp. 77-84. doi:10.1016/j.ejps.2004.09.013

[19] Y. H. Cheng, A. Margaret Dyer, I. Jabbal-Gill, M. Hinchcliffe, R. Nankervis, A. Smith and P. Watts, "Intranasal Delivery of Recombinant Human Growth Hormone (Somatropin) in Sheep Using Chitosan-Based Powder Formulations," European Journal of Pharmaceutical Sciences, Vol. 26, No. 1, 2005, pp. 9-15. doi:10.1016/j.ejps.2005.03.014

[20] X. Y. Shi and T. W. Tan, "Preparation of Chitosan/Ethylcellulose Complex Microcapsule and Its application in Controlled Release of Vitamin D2," Biomaterials, Vol. 23, No. 23, 2002, pp. 4469-4473. doi:10.1016/S0142-9612(02)00165-5

[21] A. Grenha, B. Seijo and C. Remunan-Lõpez, "Microencapsulated Chitosan Nanoparticles for Lung Protein Delivery," European Journal of Pharmaceutical Sciences, Vol. 25, No. 4-5, July-August 2005, pp. 427-437. doi:10.1016/j.ejps.2005.04.009

[22] D. S. Jiang, S. Y. Long, J. Huang, H. Y. Xiao and J. Y. Zhou, "Immobilization of Pycnoporus Sanguineus Laccase on Magnetic Chitosan Microspheres," Biochemical Engineering Journal, Vol. 25, No. 1, 2005, pp. 15-23. doi:10.1016/j.bej.2005.03.007

[23] S. Berliner, R. Ben-Amia, D. Samocha-Bonet, S. Abu-Abeid, V. Schechner, Y. Beigel, I. Shapira, S. Yed gar and G. Barshtein, "The Degree of Red Blood Cell 
Aggregation on Peripheral Blood Glass Slides Corresponds to Inter-Erythrocyte Cohesive Forces in Laminar Flow," Thrombosis Research, Vol. 114, No. 1, 2004, pp. $37-44$.

[24] P. Foresto, M. D’Arrigo, L. Racca, F. Filippini, R. Gallo, J. Valverde and R. J. Rasia, "Comparative Analysis of Aggregate Shapes by Digitized Microscopic Images. Application to Hypertension," Clinical Hemorheology and Microcirculation, Vol. 26, No. 3, 2002, pp. 137-144.

[25] K. Milowska and T. Gabryelak, "Enhancement of Ultrasonically Induced Cell Damage by phthalocyanines in $\mathrm{Vi}$ tro," Ultrasonics, Vol. 48, No. 8, 2008, pp. 724-730.

[26] N. Sankararamakrishnan and R. Sanghi, "Preparation and Characterization of a Novel Xanthated Chitosan," Carbohydrate Polymers, Vol. 66, No. 2, 2006, pp. 160-167. doi:10.1016/j.carbpol.2006.02.035

[27] J. I. Zhang, S. Zhang, Y. Wang and J. Zeng, "Composite Magnetic Microspheres Preparation and Characteriza- tion," Journal of Magnetism and Magnetic Materials, Vol. 309, No. 2, 2007, pp. 197-201. doi:10.1016/j.jmmm.2006.06.035

[28] H. L. Bao, Z. M. Chen, L. Kang, P. H. Wu and J. Z. Liu, "Preparation of Magnetic Nanoparticles Modified by Amphiphilic Copolymers," Materials Letters, Vol. 60, No. 17-18, 2006, pp. 2167-2170. doi:10.1016/j.matlet.2005.12.092

[29] D. Horaka, E. Petrovskyb, A. Kapickab and T. Frederichsc, "Synthesis and Characterization of Magnetic Poly (Glycidyl Methacrylate) Microspheres," Journal of Magnetism and Magnetic Materials, Vol. 311, No. 2, 2007, pp. 500-506. doi:10.1016/j.jmmm.2006.08.006

[30] J. De-Sheng, L. Sheng-Ya, J. Huang, X. Hai-Yan and Z. Ju-Ying, "Immobilization of Pycnoporus Sanguineus Laccase on Magnetic Chitosan Microspheres," Biochemical Engineering Journal, Vol. 25, No. 1, 2005, pp. 15-23. doi:10.1016/j.bej.2005.03.007 